\title{
Grey Relational Analysis Parameter-Based Predictive Modelling of Surface Roughness
}

\author{
Zvikomborero Hweju, Khaled Abou-El-Hossein* \\ Ultra-High Precision Engineering Research Unit, Department of Mechatronics, Nelson Mandela University, \\ Port Elizabeth, South Africa
}

Received May 19, 2021; Revised September 22, 2021; Accepted October 17, 2021

\begin{abstract}
Cite This Paper in the following Citation Styles
(a): [1] Zvikomborero Hweju, Khaled Abou-El-Hossein, "Grey Relational Analysis Parameter-Based Predictive Modelling of Surface Roughness," Universal Journal of Mechanical Engineering, Vol. 9, No. 3, pp. 21 - 26, 2021. DOI: 10.13189/ujme.2021.090301.
\end{abstract}

(b): Zvikomborero Hweju, Khaled Abou-El-Hossein (2021). Grey Relational Analysis Parameter-Based Predictive Modelling of Surface Roughness. Universal Journal of Mechanical Engineering, 9(3), 21 - 26. DOI: 10.13189/ujme.2021.090301.

Copyright $\odot 2021$ by authors, all rights reserved. Authors agree that this article remains permanently open access under the terms of the Creative Commons Attribution License 4.0 International License

\begin{abstract}
Grey relational analysis is a widely used approach for the purposes of decision making, prediction and relational investigation. This study utilizes the grey relational analysis for modelling surface roughness during the single point diamond turning of RSA-443. The utilized parameter in this study is the grey relational grade together with cutting speed, feed, and depth of cut. The Taguchi L9 orthogonal array has been utilized for designing the experiment, with three extra experimental runs being carried out for the purposes of validating the developed model. The developed model indicates that the cutting parameters are insignificant as predictors of surface roughness. Grey relational grade is the only significant predictor of surface roughness. Acoustic emission signal root mean square has been used for determining the grey relational grade in the study. The grey relational analysis-based surface roughness values have been compared to experimentally obtained values by using the Mean Absolute Percentage Error (MAPE). The accuracy levels are an exhibition of high prediction power of the model. Pair t-test results indicate the lack of statistical significance in the difference between the experimentally measured and predicted surface roughness values.
\end{abstract}

Keywords Grey Relational Analysis, Surface Roughness, RSA-443, Predictive Modelling

\section{Introduction}

Single point diamond turning is a mechanical machining process that utilizes a cutting tool with a diamond tip to manufacture high quality aspheric and cylindrical components. Numerous techniques have been utilized to optimize and predict surface roughness in mechanical machining of components. One of the methods that have been employed is the grey relational analysis technique. Panda et al. utilized the technique to model and optimize cutting parameters in dry machining of AISI 52100 steel using a mixed ceramic insert tool [1]. In the study, first and second order models were developed for the purposes of response accuracy checking. There is a good correlation between the developed models and experimentally obtained surface roughness values. Hence, the grey relational analysis technique is efficient in modelling and predicting surface roughness.

In yet another study, Tosun [2] used the grey relational analysis technique to determine the optimum parameters for multi-performance characteristics in drilling of AISI 4140 steel. In the study, the following parameters have been used as drilling parameters: feed rate, cutting speed, drill and point angles. The experiment has been designed using the Taguchi orthogonal array. The study results indicate a significant enhancement of surface roughness and blur through using the grey relational analysis technique. In a similar study, Kao et al. [3] optimized the electrochemical polishing of 316L stainless steel using grey relational analysis. In the study, the control variables 
are temperature, current density, and electrolyte composition, while the response variables are surface roughness and passivation strength. The results of the study successfully verified the effectiveness of the approach. Additionally, numerous studies have successfully used the same approach [4-6], albeit on materials other than RSA-443.

A study by Yang et al. [7] has utilized the grey relational analysis technique to optimize the machining parameters during the end milling of high purity graphite. The machining parameters in the study are cutting speed, depth of cut and feed rate, while the response variables are surface roughness and groove width.

The grey relational analysis approach was successfully used by $\mathrm{Lu}$ et al. [8] in conjunction with principal component analysis (PCA) to optimize process parameters during the in-feed centerless cylindrical grinding of EN52 steel. The use of the technique has proven to be efficient.

Based on the previous studies, it is evident that the Grey relational analysis technique is a powerful optimization tool that can be reliably used for machining processes such as milling, drilling, and turning. Hence, this paper is a presentation of grey relational analysis-based optimization of machining parameters in single point diamond turning of RSA 433.

\section{Grey Relational Analysis}

The grey relational analysis is a technique utilized to determine the influence and interrelationship among multiple parameters. It reduces multi response optimization problem into a single response relational grade. The stages of transformation are presented by the flow chat (Figure 1).

The first stage entails experimentally obtained data normalization. The normalization method employed is the mean-max method. This procedure performs a linear alteration on the original data. The data values are normalized in the range $[0,1]$. The normalization equation is presented by (1). In this study, data normalization has been performed to remove inconsistences that can complicate data analysis. The inconsistences may be due to any of the following: inserting more information than required, deleting data, or updating existing data.

$$
\mathrm{Z}=(\gamma \text {-mina }) /(\operatorname{maxa}-\mathrm{mina})
$$

Where $\mathrm{Z}=$ normalized value

$\gamma=$ new value in the required range mina $=$ minimum value in the required range maxa $=$ maximum value in the required range

Immediately following the data normalization stage is the computation of the deviation sequence using (2).

$$
\Delta \mathrm{oi}(\mathrm{k})=[\mathrm{X} 0(\mathrm{k})-\mathrm{Xi}(\mathrm{k})]
$$

Where $\Delta \mathrm{oi}(\mathrm{k})=$ deviation sequence $\mathrm{X} 0(\mathrm{k})=$ reference sequence
$\mathrm{Xi}(\mathrm{k})=$ comparability sequence

The grey relational coefficient (GRC) is calculated using (3).

$$
\alpha \mathrm{i}(\mathrm{k})=(\Delta \min +\alpha \Delta \max ) /(\Delta \mathrm{d}(\mathrm{k})+\alpha \Delta \max )
$$

where $\alpha \mathrm{i}(\mathrm{k})=$ grey relational coefficient

$\Delta \min =$ minimum absolute difference

$\Delta \max =$ maximum absolute difference

$\Delta \mathrm{d}=$ deviation sequence

Finally, a composite grey relational grade (GRG), is determined by averaging the GRC of each response variable as shown in (4).

$$
\chi \mathrm{i}=(1 / \mathrm{n}) \sum \alpha_{\mathrm{i}}(\mathrm{k})
$$

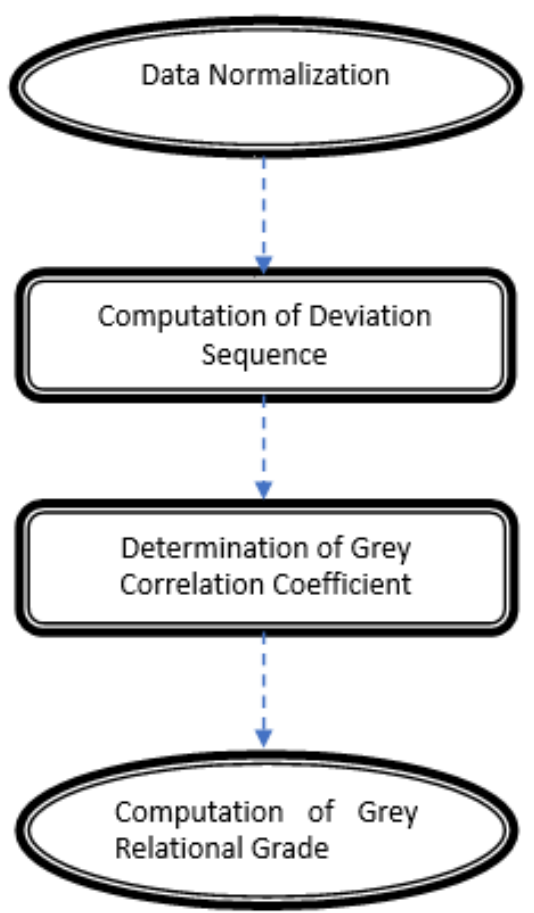

Figure 1. Grey Relational Analysis Process Flow

\section{Materials and Methodology}

In the present study, kerosene has been used as the coolant during the ultra-high precision diamond turning of RSA-443. The experiment has been designed using the Taguchi L9 orthogonal array and an extra three (3) experimental runs have been carried out for the purpose of testing the accuracy of the developed model. During the turning process, acoustic emission signals are captured, and the root mean square of the signal is employed for modelling purposes together with primary cutting parameters (cutting speed, feed rate and depth of cut). The stages followed in performing the experiment are presented by the flow diagram (Figure 2). 


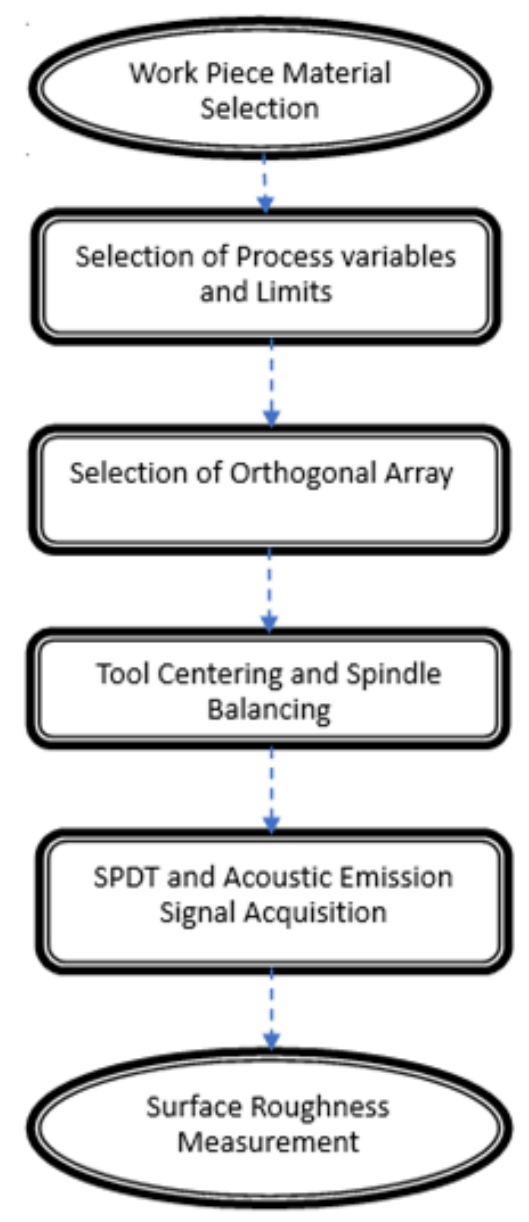

Figure 2. Experimentation Process Flow Chart
The first stage has been the selection of workpiece material. Use has been made of a $60 \mathrm{~mm}$ diameter specimen of RSA-443. RSA-443 contains $40 \%$ silicon by composition. Three levels for each of the three selected process parameters have been decided. Prior to performing the machining process, the single point diamond cutting tool has been centered, and the spindle balanced as a way of eliminating unwanted oscillations. In this study, spindle balancing has been carried out at 2500 rpm, 2 000rpm and $1000 \mathrm{rpm}$. The selected balancing values cover all chosen cutting speed levels. The diamond cutting tool centering image is presented in Figure 3.

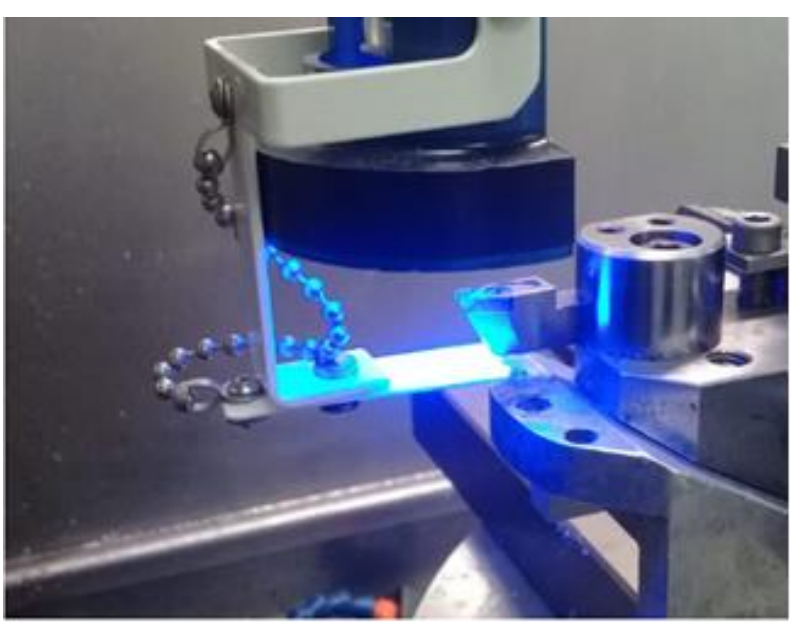

Figure 3. Diamond Cutting Tool Centering

\section{Results and Analysis}

The experimental results of the single point diamond turning process are presented in Table 1. The resultant surface roughness for each cutting parameter combination has been presented.

Table 1. Single Point Diamond Turning Results (Kerosene Coolant)

\begin{tabular}{|c|c|c|c|c|c|}
\hline Run No. & Cutting Speed $(\mathbf{r p m})$ & Feed $(\mathbf{m m} / \mathbf{m i n})$ & Depth of Cut $(\boldsymbol{\mu m})$ & AErms $(\mathbf{V})$ & $\mathbf{R}_{\mathbf{a}}(\mathbf{n m})$ \\
\hline 1 & 1250 & 7.5 & 5 & 0.029679 & 21 \\
\hline 2 & 1250 & 15 & 15 & 0.027504 & 33 \\
\hline 3 & 1250 & 22.5 & 25 & 0.028245 & 38 \\
\hline 4 & 1750 & 7.5 & 15 & 0.02781 & 17 \\
\hline 5 & 1750 & 15 & 25 & 0.027856 & 23 \\
\hline 6 & 1750 & 22.5 & 5 & 0.028368 & 26 \\
\hline 7 & 2500 & 7.5 & 25 & 0.027855 & 12 \\
\hline 8 & 2500 & 15 & 5 & 0.034323 & 18 \\
\hline 9 & 2500 & 22.5 & 15 & 0.028314 & 19 \\
\hline 10 & 1250 & 7.5 & 15 & 0.030895 & 24 \\
\hline 11 & 1750 & 15 & 5 & 0.027612 & 23 \\
\hline 12 & 2500 & 22.5 & 25 & 0.02721 & 22 \\
\hline
\end{tabular}


Table 2. Normalized Data

\begin{tabular}{|c|c|c|c|c|c|}
\hline Run No. & Cutting Speed $(\mathbf{r p m})$ & Feed $(\mathbf{m m} / \mathbf{m i n})$ & Depth of Cut $(\boldsymbol{\mu m})$ & AErms $(\mathbf{V})$ & $\mathbf{R}_{\mathbf{a}}(\mathbf{n m})$ \\
\hline 1 & 0.00 & 0.00 & 0.00 & 0.32 & 0.35 \\
\hline 2 & 0.00 & 0.50 & 0.50 & 0.00 & 0.81 \\
\hline 3 & 0.00 & 1.00 & 1.00 & 0.11 & 1.00 \\
\hline 4 & 0.40 & 0.00 & 0.50 & 0.04 & 0.19 \\
\hline 5 & 0.40 & 0.50 & 1.00 & 0.05 & 0.42 \\
\hline 6 & 0.40 & 1.00 & 0.00 & 0.13 & 0.54 \\
\hline 7 & 1.00 & 0.00 & 1.00 & 0.05 & 0.00 \\
\hline 8 & 1.00 & 0.50 & 0.00 & 1.00 & 0.23 \\
\hline 9 & 1.00 & 1.00 & 0.50 & 0.12 & 0.27 \\
\hline 10 & 0.00 & 0.00 & 0.50 & 0.95 & 0.22 \\
\hline 11 & 0.40 & 0.50 & 0.00 & 0.62 & 0.67 \\
\hline 12 & 1.00 & 1.00 & 1.00 & 0.58 & 0.61 \\
\hline
\end{tabular}

Table 3. Grey Relational Coefficient and Grey Relational Grade Values

\begin{tabular}{|c|c|c|c|c|c|c|}
\hline Run & \multicolumn{2}{|c|}{ Evaluation of $\boldsymbol{\Delta}_{\mathbf{o i}}$} & \multicolumn{2}{c|}{ Grey Relational Coefficient } & GRG & Rank \\
\hline & $\mathrm{AE}_{\mathrm{rms}}$ & $\mathrm{R}_{\mathrm{a}}$ & $\mathrm{AE}_{\mathrm{rms}}$ & $\mathrm{R}_{\mathrm{a}}$ & & \\
\hline 1 & 0.68 & 0.65 & 0.424 & 0.435 & 0.429 & 5 \\
\hline 2 & 1.00 & 0.19 & 0.333 & 0.725 & 0.529 & 7 \\
\hline 3 & 0.89 & 0.00 & 0.360 & 1.000 & 0.680 & 11 \\
\hline 4 & 0.96 & 0.81 & 0.342 & 0.382 & 0.362 & 2 \\
\hline 5 & 0.95 & 0.58 & 0.345 & 0.463 & 0.404 & 4 \\
\hline 6 & 0.87 & 0.46 & 0.365 & 0.521 & 0.443 & 6 \\
\hline 7 & 0.95 & 1.00 & 0.345 & 0.333 & 0.339 & 1 \\
\hline 8 & 0.00 & 0.77 & 1.000 & 0.394 & 0.697 & 12 \\
\hline 9 & 0.88 & 0.73 & 0.362 & 0.407 & 0.384 & 3 \\
\hline 10 & 0.05 & 0.78 & 0.909 & 0.391 & 0.650 & 10 \\
\hline 11 & 0.38 & 0.33 & 0.568 & 0.602 & 0.585 & 9 \\
\hline
\end{tabular}

Table 2 is a presentation of the normalized experimental data and results.

A presentation is made of the calculated values of the grey relational coefficient and grey relational grade values (Table 3). The computed rank is presented in the extreme right column of the table. Surface roughness values based on machining parameters and grey relational coefficient are presented in Table 4. The data is subsequently used to generate a model linking grey relational grade (GRG) and surface roughness. This model is essential as it adds to the already available surface roughness prediction tools during single point diamond turning of rapidly solidified aluminium (RSA-443).

Performing multiple linear regression to ascertain the correlation between grey relation grade and surface roughness yields (5).

$$
\mathrm{Y}=-8.967336+73.060687 \mathrm{GRG}
$$

$\mathrm{R}$ square $\left(\mathrm{R}^{2}\right)$ equals 0.901298 . It means that the predictors (Xi) explain $90.1 \%$ of the variance of $\mathrm{Y}$. Adjusted R square equals 0.881557 . The coefficient of multiple correlation $(\mathrm{R})$ equals 0.949367 . It means that there is a very strong direct relationship between the predicted data $(\hat{y})$ and the observed data $(y)$. Overall regression: right-tailed, $\mathrm{F}(1,5)=45.657386$, $\mathrm{p}$-value $=$ 0.00107809 . Since p-value $<\alpha(0.05)$, we reject the H0. The linear regression model (2) provides a better fit than the model without the independent variables resulting in, $\mathrm{Y}=\mathrm{b} 0$. The following independent variables are not significant as predictors for $\mathrm{Y}$ : X1, X2, and X3. Therefore, the calculator excluded these variables from the model.

$$
\mathrm{Y}=\mathrm{b} 0+\mathrm{b} 1 \mathrm{X} 1+\ldots+\mathrm{BpXp}
$$


Table 4. Surface Roughness Based on Machining Parameters and Grey Relational Coefficient

\begin{tabular}{|c|c|c|c|c|c|c|c|}
\hline \multirow{2}{*}{$\mathrm{C}_{1[\mathrm{rpm}]}$} & \multirow{2}{*}{$\mathbf{C}_{2[\mathrm{~mm} / \mathrm{min}]}$} & \multirow{2}{*}{$\mathrm{C}_{3[\mu \mathrm{m}]}$} & \multicolumn{2}{|c|}{ GRC } & \multirow{2}{*}{$\begin{array}{c}\text { Measured Ra } \\
{[\mathrm{nm}]}\end{array}$} & \multirow{2}{*}{$\begin{array}{c}\text { Predicted Ra } \\
{[\text { [nm] }}\end{array}$} & \multirow{2}{*}{$\begin{array}{c}\text { Absolute Error } \\
(\%)\end{array}$} \\
\hline & & & AErms [V] & $\mathrm{Ra}[\mathrm{nm}]$ & & & \\
\hline 1250 & 7.5 & 5 & 0.424 & 0.435 & 21 & 22.375 & 6.54 \\
\hline 1250 & 15.0 & 15 & 0.333 & 0.725 & 33 & 29.681 & 10.05 \\
\hline 1250 & 22.5 & 25 & 0.360 & 1.000 & 38 & 40.713 & 7.13 \\
\hline 1750 & 7.5 & 15 & 0.342 & 0.382 & 17 & 17.480 & 2.82 \\
\hline 1750 & 15.0 & 25 & 0.345 & 0.463 & 23 & 20.549 & 10.65 \\
\hline 1750 & 22.5 & 5 & 0.365 & 0.521 & 26 & 23.398 & 10.00 \\
\hline 2500 & 7.5 & 25 & 0.345 & 0.333 & 12 & 15.800 & 31.66 \\
\hline 2500 & 15.0 & 5 & 1.000 & 0.394 & 18 & 22.375 & 24.30 \\
\hline 2500 & 22.5 & 15 & 0.362 & 0.407 & 19 & 19.087 & 0.45 \\
\hline 1250 & 7.5 & 15 & 0.909 & 0.391 & 24 & 38.522 & 60.51 \\
\hline 1750 & 15 & 5 & 0.568 & 0.602 & 23 & 33.773 & 46.83 \\
\hline 2500 & 22.5 & 25 & 0.424 & 0.435 & 22 & 22.375 & 1.70 \\
\hline
\end{tabular}

Table 5. Paired t-test Parameters

\begin{tabular}{|c|c|}
\hline Parameter & Value \\
\hline Average $\left(\mathrm{X}_{\mathrm{d}}\right)$ & 2.51 \\
\hline Sample Size $(\mathrm{n})$ & 12 \\
\hline Sample SD $\left(\mathrm{S}_{\mathrm{d}}\right)$ & 5.37 \\
\hline Skewness & 1.27 \\
\hline Normality p-value & 0.06 \\
\hline Outliers $_{\mathrm{d}}$ & 14.52 \\
\hline
\end{tabular}

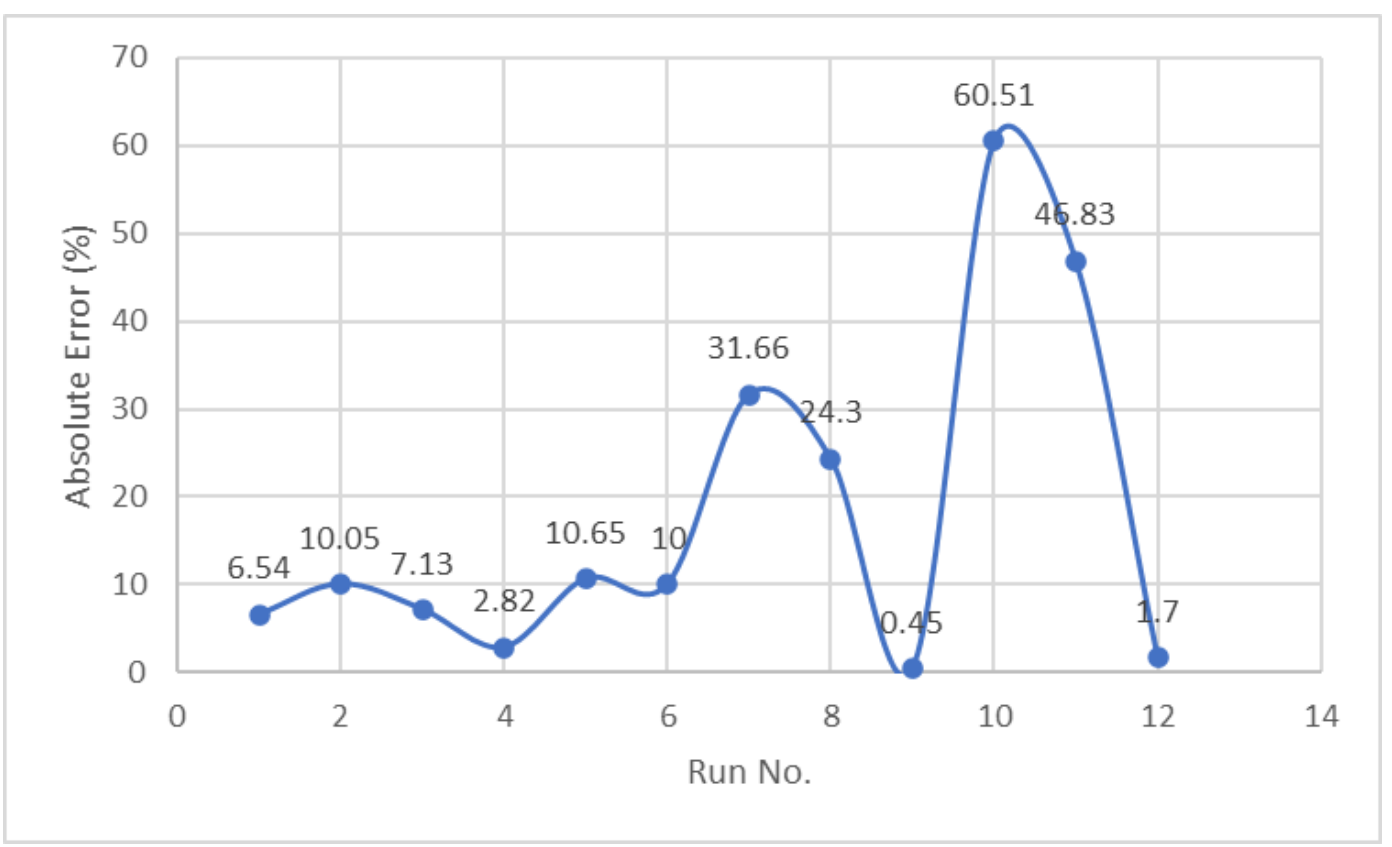

Figure 4. Plot of Absolute Error vs Run Number

The absolute percentage error values have been plotted against experiment run number to have a visual variation of the errors (Figure 4). The first eight (8) sets of absolute error values are obtained using training data, while the last four (4) values are obtained using testing data. Except for the two absolute error values at experiment run numbers
10 and 11 that have magnitudes of $60.51 \%$ and $46.83 \%$, respectively, the rest of the values are below $30 \%$. This is an indication of the high prediction accuracy of the formulated model. To assess the significance of the difference between the actual and predicted values of surface roughness, a paired t-test is conducted. The 
parameters of the paired t-test are presented in Table 5. Since p-value $>\alpha, \mathrm{H} 0$ cannot be rejected. The average of population of Predicted Value minus Actual Value is assumed to be equal to the $\mu 0$. In other words, the difference between the average of Predicted Value minus Actual Value and the $\mu 0$ is not big enough to be statistically significant.

\section{Conclusion}

This study evaluated the effectiveness of using the grey relational grade parameter in modelling surface roughness during single point diamond turning of RSA-443. The modelling results reveal the insignificance of primary cutting parameters as predictors of surface roughness in the presence of grey relational grade. High R2 value (0.9) of the model indicates a very strong direct relationship between the grey relational grade and the surface roughness. Predicted surface roughness values of the formulated model have been compared to the experimentally obtained values using the Mean Absolute Percentage Error (MAPE) method. The MAPE values indicate high prediction accuracy of the model. Furthermore, a paired t-test indicates the lack of statistical significance in the difference between the experimentally measured and predicted surface roughness values. Hence, the grey relational grade is a suitable and accurate predictor of surface roughness.

\section{REFERENCES}

[1] Panda A., Sahoo A. K., Rout A. K., "Multi-attribute decision making parametric optimization and modeling in hard turning using ceramic insert through grey relational analysis: A case study," Decision Science Letters, vol. 5, no. 4, pp. 581-592, 2016. DOI: 10.5267/j.dsl.2016.3.001

[2] Tosun N., "Determination of optimum parameters for multi-performance characteristics in drilling by using grey relational analysis," International Journal Advanced Manufacturing Technology, vol. 28, pp. 450-455, 2006. DOI 10.1007/s00170-011-3857-6

[3] Kao P. S., Hocheng H., "Optimization of electrochemical polishing of stainless steel by grey relational analysis," Journal of Materials Processing Technology, vol. 140, no. 1-3, pp. 255-259, 2006. DOI: 10.1016/S0924-0136(03)007 47-7

[4] Lin J. L., Lin C. L., "The use of the orthogonal array with grey relational analysis to optimize the electrical discharge machining process with multiple performance characteristics," International Journal of Machine Tools and Manufacture vol. 42, no. 2, pp. 237-244, 2002. DOI:10.1016/S0890-6955(01)00107-9

[5] Çaydaş U., Hasçalık A., "Use of the grey relational analysis to determine optimum laser cutting parameters with multi-performance characteristics," Optics \& Laser Technology, vol. 40, no. 7, pp. 987-994, 2008. DOI: 10.1016/j.optlastec.2008.01.004

[6] Huang J. T., Liao Y. S., "Optimization of machining parameters of Wire-EDM based on Grey relational and statistical analyses," International Journal of Production Research, vol. 41, no. 8, pp. 1707-1720, 2003.

[7] Yang Y. Y., Shie J. R., Huang C. H., "Optimization of dry machining parameters for high purity graphite in end-milling process," Materials and Manufacturing Processes, vol. 21, no. 8, pp. 832 - 837, 2006. DOI: $10.1080 / 03602550600728141$

[8] Lu H. S., Chang C. K., Hwanga N. C., Chung C. T., " Grey relational analysis coupled with principal component analysis for optimization design of the cutting parameters in high-speed end milling," Journal of Material Processes Technology, 2008. DOI:10.1016/j.jmatprotec. 2008.08.030 